\title{
PRIMARY PULMONARY HYPERTENSION IN THREE SIBS
}

\author{
BY \\ P. N. COLEMAN, A. W. B. EDMUNDS, AND J. TREGILLUS \\ From the Friarage Hospital, Northallerton, and the Memorial Hospital, Darlington \\ Received January 4, 1958
}

The number of well-documented reports of the findings in primary pulmonary hypertension is increasing rapidly, but the ætiology remains obscure. A review of the published series reveals two possible clues. First, most of them show a significant female preponderance and, secondly, some suggest that primary pulmonary hypertension can be familial. Thus Dresdale et al. (1954) deseribed three cases, mother and son and the mother's sister, all of whom died of right heart failure. Cardiac catheterization in the mother and son demonstrated severe pulmonary hypertension and showed no congenital cardiac defects, and in the case of the sister the diagnosis was based on clinical, electrocardiographic, and radiological findings: a brother of the mother died of undiagnosed heart disease at an early age. Clarke et al. (1927) in a paper on lesions of the pulmonary arteries described two sisters: one of them died in heart failure at the age of $5 \frac{1}{2}$ years, and necropsy showed a dilated and hypertrophied right heart with no septal defects and marked atheroma of the pulmonary arteries; the other sister, aged 7 years, was cyanosed and dyspnœic and showed clinical evidence of right ventricular hypertrophy. Lange (1948) described a family of 186 members of whom 82 were said to be cyanosed: of 42 members personally examined, 30 were cyanosed and 10 had an accentuated pulmonary second sound; 13 out of 21 examined radiologically had an enlarged pulmonary conus, and some had cardiographic evidence of right ventricular preponderance: none of these cases came to necropsy. Because of lack of post-mortem confirmation, this evidence, though suggesting that primary pulmonary hypertension can be familial, remains inconclusive. For this reason we report the findings in a brother and two sisters who died of primary pulmonary hypertension confirmed in each case by necropsy.

\section{Case Reports}

Case 1. The patient, a 22-year-old housewife, was admitted to hospital under the care of Mr. J. S. Hovell in the 36th week of her third pregnancy, because she had developed a cough and dyspnoa. She had had diphtheria at the age of 6 years, but otherwise her health had been good and her previous pregnancies uneventful. On admission moist sounds were heard at both lung bases. Labour, four days later proceeded normally, lasting two hours, but immediately afterwards her condition deteriorated, and she was seen by one of us (A. W. B. E.) four hours later. She was then breathless and cyanosed; there was no odema and the jugular venous pressure was not increased. The heart rate was 100 a minute with regular rhythm and the blood pressure was 120/90. On auscultation the lungs were clear; a presystolic murmur was heard at the apex and an early diastolic murmur below the pulmonary area. She was thought to have mitral stenosis and aortic incompetence with impending pulmonary œdema. In spite of treatment, she collapsed suddenly and died, early on the following day.

Necropsy. The body was that of a well-built young woman. There were $300 \mathrm{ml}$. of fluid in each pleural cavity and a moderate excess in the pericardial sac. The heart $(380 \mathrm{~g}$.) was enlarged, with dilatation of the right atrium and dilatation and hypertrophy of the right ventricle. The pulmonary artery and its main branches appeared of normal calibre and contained small flecks of atheroma. The lungs were a little congested and there was some basal collapse. Apart from passive congestion the other organs were normal.

Histology. Significant changes were limited to the pulmonary arterial tree. The most striking feature G 
was an extensive intimal proliferation which was seen in vessels ranging from elastic arteries of $3 \mathrm{~mm}$. external diameter down to the smallest arterioles.

In the elastic arteries there was focal concentric proliferation of the intima with typical atheromatous degeneration but little arterial occlusion. A large proportion of the muscular arteries were similarly affected by a focal intimal proliferation, consisting of concentrically arranged fibroblasts with a variable proportion of collagen and occasional elastic fibres. In the small muscular arteries, in the range 100-300 $\mu$ external diameter, intimal proliferation often caused a serious degree of occlusion (Fig. 1). Occlusion of some muscular arteries was almost complete but it was usually possible to make out a concentric arrangement of the fibroblasts around what appeared to be the remains of the original central lumen. In some arteries, however, the intimal proliferation was eccentric (Fig. 2). No recent thrombi were seen.

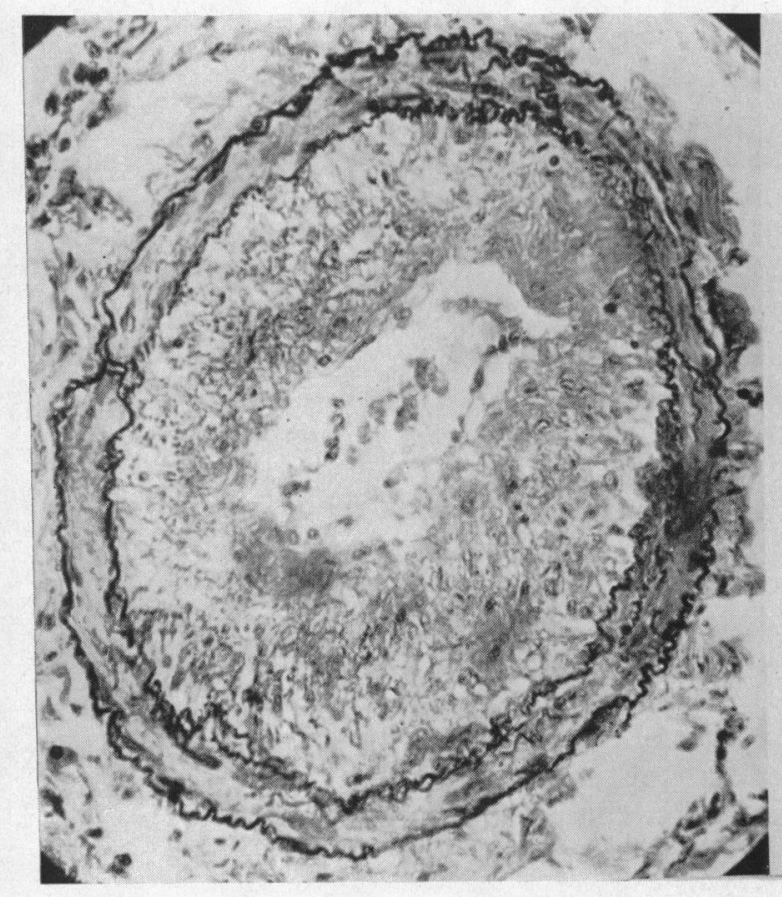

Fig. 1.-Case 1. Muscular artery $220 \mu$ external diameter. Occlusion by intimal proliferation: appearance suggests organization of thrombus. All sections were stained with Verhoeff's elastic stain and van Gieson. Magnification $\times 350$.

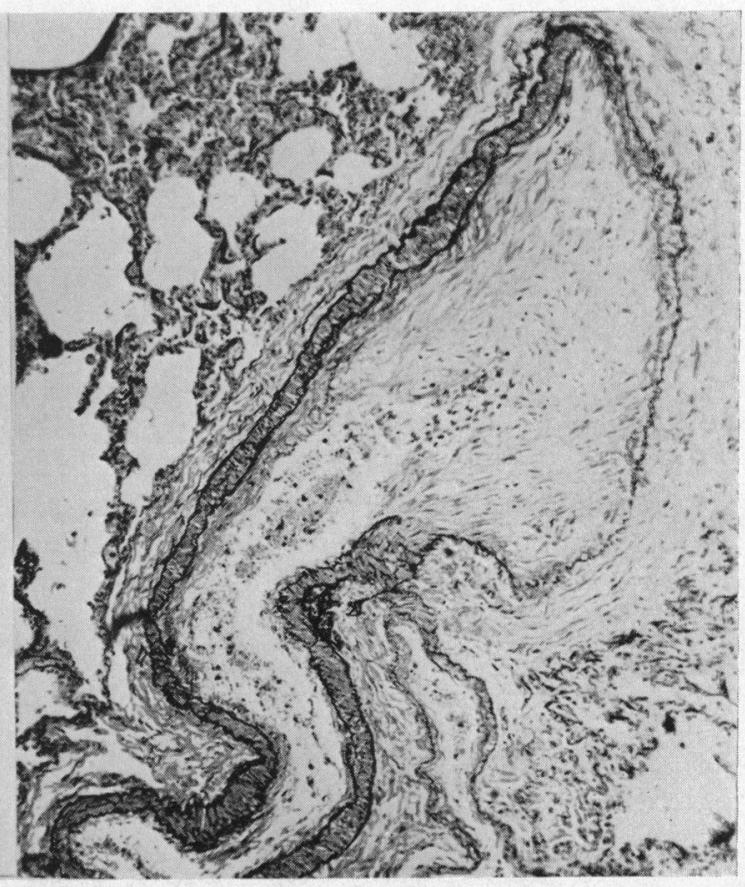

FIG. 2.-Case 1. Muscular artery, $220 \mu$ external diameter, in centre of figure. Eccentric intimal proliferation with thinning of the adjacent media. $\times 70$.

The media in the majority of the muscular arteries was normal but in a small proportion there was focal thinning; the muscle fibres were absent from a segment of the vessel wall, and there was fragmentation of the internal elastic lamina or fusion of the internal and external elastic laminæ to form a single lamina (Fig. 2). This medial thinning was always associated with intimal proliferation and tended to occur in the vicinity of branching; outward bulging of the vessel wall was not seen.

An unusually large proportion of small muscular arteries of external diameter of about $100 \mu$ were present, all showing almost complete occlusion by intimal proliferation. Occasional very small arteries were seen with external diameters down to $60 \mu$ (Fig. 3). The majority of the arterioles were completely or almost completely blocked by intimal proliferation (Fig. 4).

Case 2. After the death of Case 1 we heard from the family doctor (Dr. J. H. Beilby) that a sister had died at the age of 35 years, also from primary pulmonary hypertension, in Ashford Hospital, Middlesex. She was a married woman with three children. She had remained well apart from diphtheria when 20 and a cough dating from measles at the age of 4 . Her first two pregnancies were uneventful, but a month before 


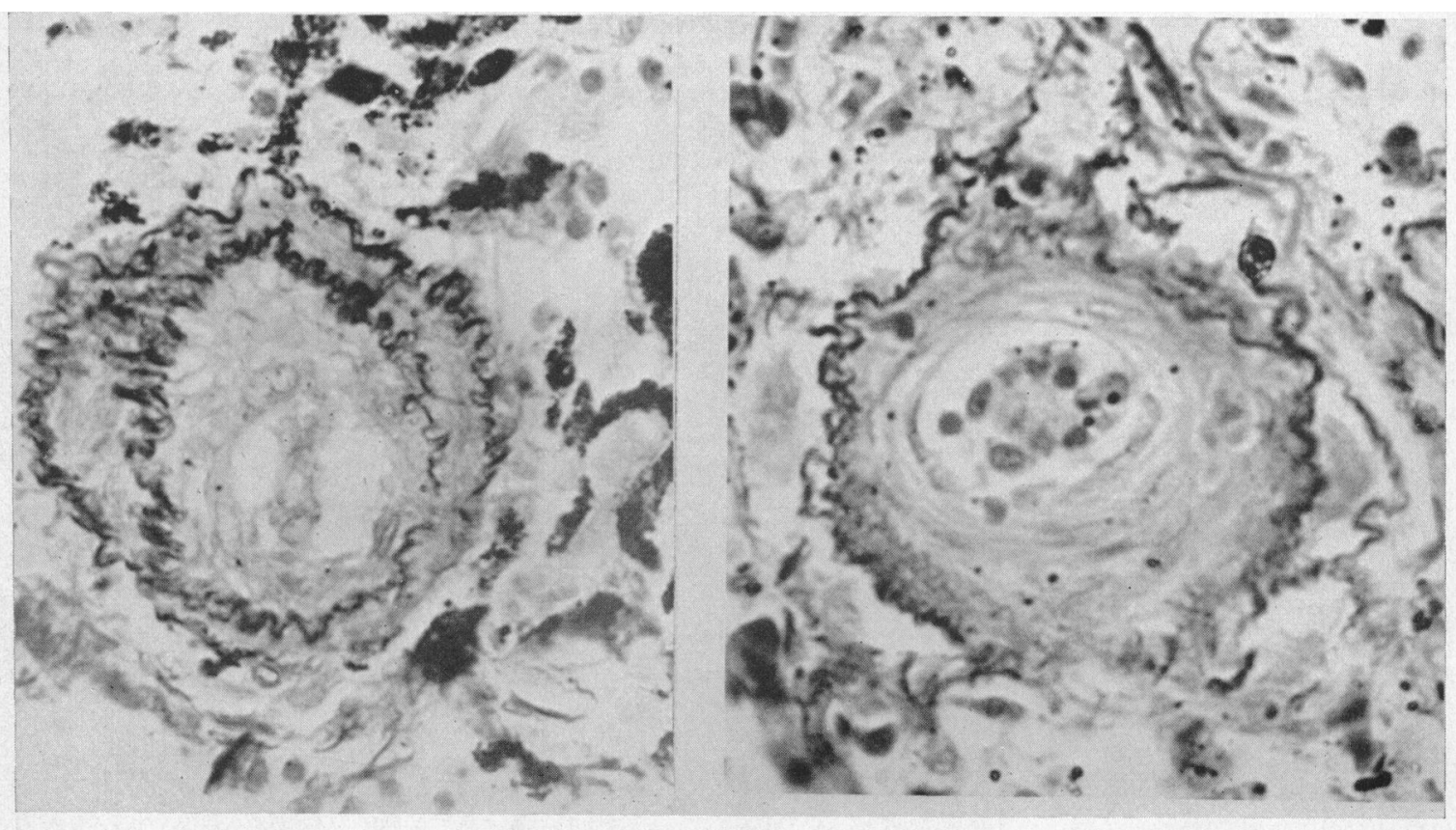

FIG. 3.-Case 1. Very small muscular artery, $60 \mu$ external diameter, intimal proliferation. Compare the arteriole in Fig. 4 which was taken at the same magnification.

Fig. 4.-Case 1. Arteriole, $60 \mu$ external diameter, occluded by intimal proliferation. $\times 800$. $\times 800$.

her third confinement she became breathless and was noticed to be cyanosed. Labour was normal but the dyspnœa persisted. Her appetite became poor and she lost $21 \mathrm{lb}$. in weight; her periods did not reappear. A year after the onset of these symptoms she was first seen by Dr. K. D. Keele, to whom we are indebted for details of this case. She was found to be slightly cyanosed; there was no clubbing of the fingers, no increase of jugular venous pressure, and no œdema. Blood pressure was 120/90. The heart rhythm was regular; the cardiac impulse was heaving. The pulmonary second sound was exaggerated and not split, but a short early diastolic murmur was audible at the pulmonary area and below. On screening the heart showed enlargement of the right ventricle and an enlarged pulmonary conus. The hilar vascular shadows were not unduly prominent but showed pulsation. The left atrium was not enlarged. An electrocardiogram showed gross right heart preponderance.

She became increasingly dyspnœic on effort during the next two years, and towards the end of this period she was admitted to hospital with ankle œdema which had first appeared a month before. She was cyanosed and in congestive failure with hepatic enlargement. Screening again showed hilar pulsation and very large pulmonary arterial shadows. Three months later she was again admitted, this time with jaundice and gross œdema; the cardiac rhythm was still regular and the rate was 120 a minute. At this time a middiastolic murmur was just audible at the apex. A few basal crepitations were heard. While preparations were being made for venesection, she collapsed suddenly and died.

Necropsy. Necropsy was carried out by Dr. W. F. Hamilton who kindly sent us a copy of his report and also most generously made available slides and blocks from the lungs. The body was that of a rather stout woman with œdema of the ankles. There were $900 \mathrm{ml}$. of fluid in each pleural cavity and a considerable excess in the pericardial sac. The heart $(600 \mathrm{~g}$.) showed dilatation and hypertrophy of the right atrium and especially of the right ventricle. A small thrombus was adherent to the endocardium of the right ventricle. There was extensive atheroma of the pulmonary arteries and their smaller branches. Apart from basal congestion the lungs were normal. There was passive congestion of the other organs.

Histology. As in Case 1 the most striking feature was extensive intimal proliferation seen in arteries of all sizes and in the arterioles (Fig. 5 and 6). The elastic arteries also showed typical atheromatous 
degeneration. Two good examples of medial thinning were seen (Fig. 5) both in the same section but, as only three blocks were available for examination, it was not possible to form an estimate as to the frequency of this lesion. No recent thrombi were seen but in one artery the appearance of multiple small vascular channels, within a lumen otherwise completely occluded by intimal proliferation, strongly suggested the recanalization of a thrombus (Fig. 5). One muscular artery of external diameter only $110 \mu$ showed in addition to intimal proliferation, a marked crenation of the elastic laminæ, and an increase in the thickness of the wall relative to the diameter (Fig. 6).

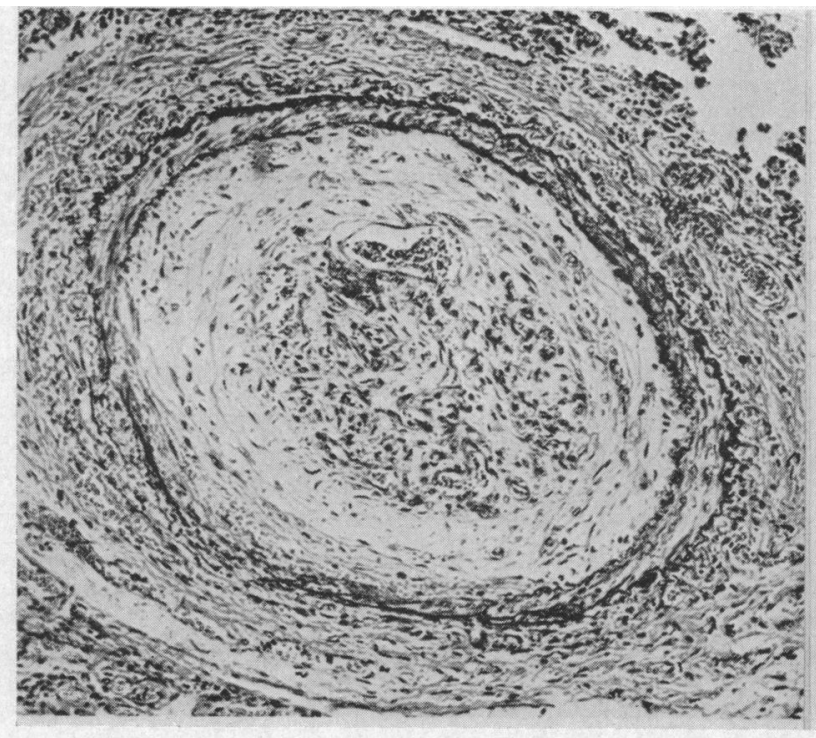

FIG. 5.-Case 2. Muscular artery $500 \mu$ external diameter. Medial thinning involving one-third of the circumference; occlusion by intimal proliferation with multiple small channels indicating recanalization of organized thrombus. (This was the only artery in Case 2 showing multiple channels, the usual arrangement being concentric fibrosis round a central lumen as in Fig. 1 and 8.) $\times 120$.

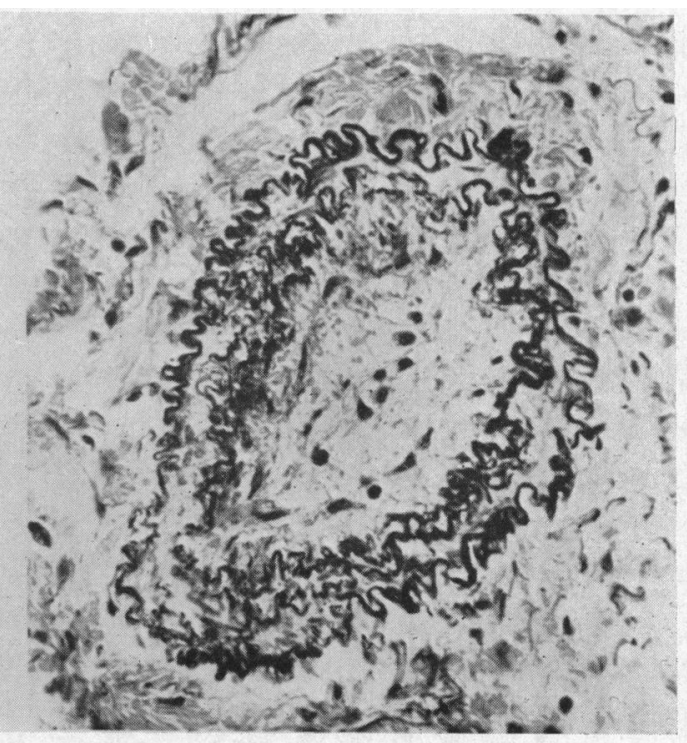

FIG. 6.-Case 2. Muscular artery, $110 \mu$ external diameter; crenation of the elastic laminæ and increase in thickness of the wall relative to the diameter. Complete occlusion by intimal proliferation. $\times 330$.

Case 3. A brother of Cases 1 and 2 was a farm worker aged 41 years when he first came under the care of one of us (A. W. B. E.). He had had a cough for many years and diphtheria at the age of 26 . Otherwise he had remained well until three months before, when, as he was feeding hay to his animals, he suddenly developed palpitation and breathlessness. He improved slowly and after a month returned to work, but a week later there was a similar episode. On examination he was not cyanosed; the heart rate was 80 , with regular rhythm. The blood pressure was $150 / 100$. The apex beat was diffuse and heaving; the pulmonary second sound was normally split and after exercise a third sound was heard to the left of the sternum. The liver was palpable four fingers' breadth below the costal margin. Screening of the chest showed some enlargement of the right ventricle. There was moderate enlargement of the pulmonary arteries which showed distinct pulsation. An electrocardiogram showed right bundle-branch block. A diagnosis of pulmonary hypertension probably secondary to an atrial septal defect was made, and he was advised to avoid strenuous exertion. A year later cyanosis appeared and gradually increased and towards the end of the year he developed œedema of the ankles and a constant dull ache over the liver. We then became aware of his relationship to Cases 1 and 2 and considered the possibility that his pulmonary hypertension was primary. Early in the following year he was admitted to hospital in congestive heart failure with deep cyanosis, gross œdema, and tender enlargement of the liver. He died after a further three months, two years after the start of his symptoms.

Necropsy. The body was that of a heavily built man with gross œdema of the legs, genitals, and sacrum. 
The heart $(750 \mathrm{~g}$.) was enlarged with dilatation and hypertrophy of the right atrium and ventricle; the thickness of the muscle of the right ventricle equalling that of the left. The heart was otherwise normal. There was a little free fluid in the pleural and pericardial cavities. The pulmonary artery and its main branches seemed dilated and showed flecks of atheroma. The lungs were a little congested. There was a greatly enlarged nutmeg liver. Apart from passive congestion the other organs were normal.

One lung was retained for microscopic examination and the other was despatched intact to Dr. D. S. Short who kindly examined it radiographically after injection of the pulmonary arteries with bismuth oxychloride in gelatin (Short, 1956). The pulmonary arteriogram (Fig. 7) showed generalized loss of the small arteries and arterioles due to arterial obstruction; an appearance seen in cases of pulmonary hypertension and likened to a pruned tree by Evans (1951).

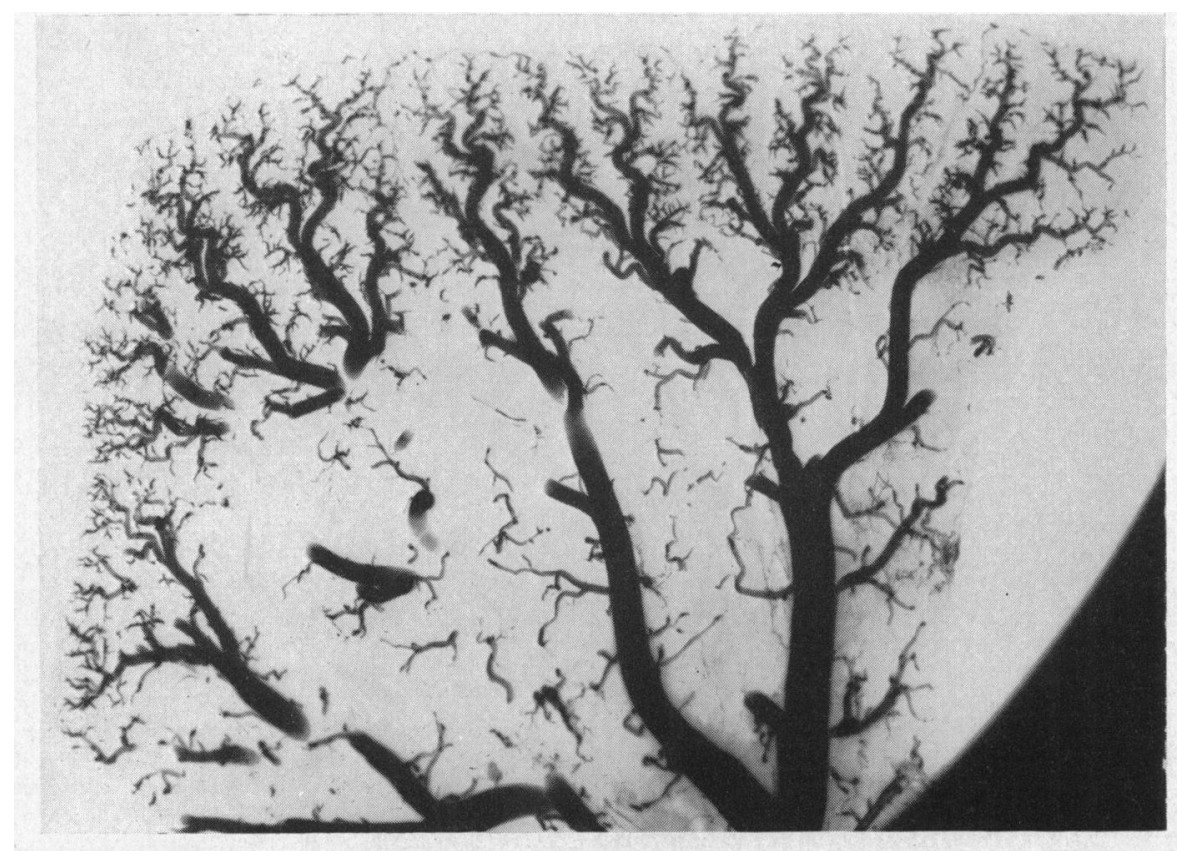

FIG. 7.-Case 3. Arteriogram shows "Pruned tree" appearance due to generalized loss of the finest arteries and arterioles.

Histology. The microscopic appearances were similar to Cases 1 and 2, though the obstruction of the muscular arteries appeared to be less extensive. However, in many of the sections there were muscular arteries that showed severe occlusion, and in some of these there was an increase in thickness of the media (Fig. 8). Many occluded arterioles were seen (Fig. 9). In occasional muscular arteries the media was completely disorganized and the muscle was partially replaced by fibrous tissue. Only very occasional examples of medial thinning were seen.

\section{FAMILY STUDIES}

The first patient (Case 1) died shortly after the birth of her third child. The baby was cyanosed from birth and died on the fourteenth day. Necropsy was carried out and revealed a large atrial septal defect and absence of the spleen. Sections were made from one lung and the other lung was sent to Dr. D.S. Short, who, after injection of the pulmonary arteries, found no evidence of any pulmonary lesion. The first child is alive and well and no abnormalities were detected in the lungs or heart on clinical examination or by radiography and electrocardiography. The second child had died within 24 hours, having been cyanosed at birth: necropsy was not carried out. Careful enquiries were made into the medical history of the other members of the family and where 
possible a general physical examination, screening of the chest and electrocardiography were carried out. A comprehensive picture of the family was obtained and this is set out in Fig. 10. Among the other ten sibs of our cases there was one brother who, apparently healthy in early infancy, died at the age of six months from "cardiac failure" after an illness of two days. In the next generation there were twelve children of whom ten are living; three of these children are referred to above. Among the others are a brother and sister, the brother has a congenital dislocation of the hip and the sister hydrocephalus.

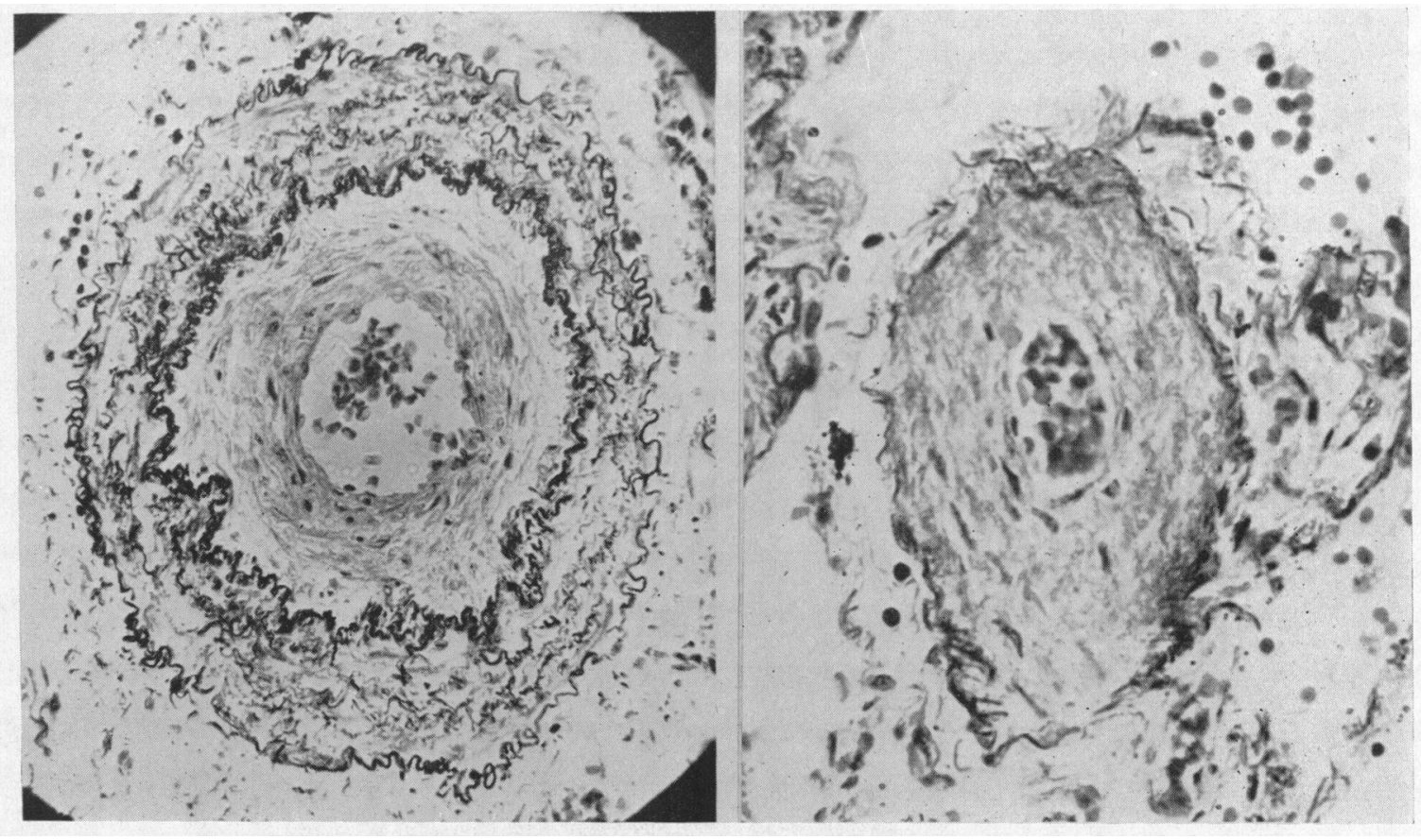

Fig. 8.-Case 3. Muscular artery, 220 $\mu$ external diameter. Fig. 9.-Case 3. Arteriole 70 $\mu$ external diameter, Arterial wall of increased thickness, showing crenation of the elastic laminæ; compare with media of arteries in Fig. 1 and 2 . Intimal proliferation. $\times 340$.

showing occlusion by intimal proliferation. $\times 680$.

\section{Discussion}

It seems highly probable that these cases of primary pulmonary hypertension were genetic in origin. All three patients were victims of an outbreak of diphtheria affecting the whole family about sixteen years before their deaths; but we know of nothing that suggests an ætiological connection between diphtheria and pulmonary hypertension and we think this association was fortuitous. It is also extremely unlikely that primary pulmonary hypertension, which is a rare disease, would occur by chance in three sibs.

The familial incidence can be explained on the basis of an inherited congenital defect, but it is difficult to pick out a feature that can be regarded as a primary lesion from the complicated picture presented by the histology. Special consideration must be given to the occurrence of medial thinning in some of the muscular arteries. Evans and his colleagues have found focal thinning of the media of the muscular arteries in many cases of pulmonary hypertension. They consider that the lesions are foci of congenital hypoplasia of the media and that intimal proliferation occurring in their vicinity, as a reparative process, initiates the hypertension (Gilmour and Evans, 1946; Evans, 1951; Evans et al., 1957). The medial lesions seen in our cases were similar to those described by 


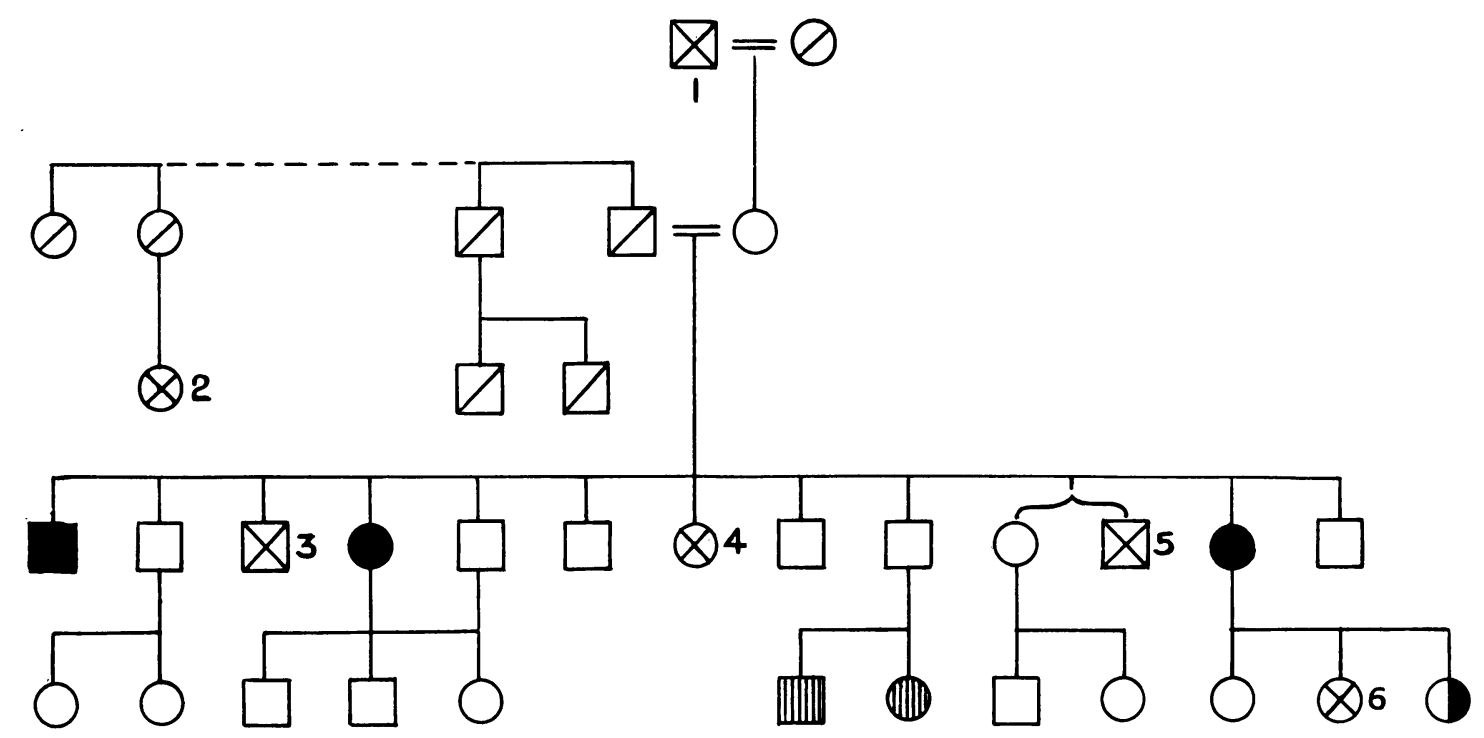

FIG. 10.

Healthy: clinical examination, radiography of chest, and electrocardiogram showed no abnormality.

Reported healthy (not examined). The father of the 13 sibs is well and aged 82 years.

Died: case of primary pulmonary hypertension.

Died aged 2 weeks: atrial septal defect and congenital absence of the spleen.

Living but have congenital defects: the boy has congenital dislocation of the hip and the girl hydrocephalus. No pulmonary or cardiac abnormalities were found in these children on clinical examination, and the chest X-rays and electrocardiograms were normal.

Died. (1) Died aged 22 years, accident. (2) Died aged 22 years, cause unknown. (3) Died aged 3 weeks with "fits." (4) Died, aged 6 months, from "cardiac failure." (5) Twin, died on second day. (6) Cyanosed from birth, died on second day.

Note: The dotted line indicated the relationship of brother to half-sisters.

Evans, but they occurred in a relatively small proportion of the total number of muscular arteries showing intimal proliferation. We are inclined to think that in our cases medial thinning was the result, rather than the cause, of the associated intimal proliferation and represented a degenerative change.

Since we have been unable to satisfy ourselves that there was an anatomical anomaly, we favour the inheritance of a defect of function as the explanation of the familial incidence. This may have operated by inducing hypertension through an increased tone in the smaller muscular arteries. The structural changes observed in the post-mortem material, in particular the intimal proliferation, must have played an important part in maintaining the hypertension in the later stages of the disease; but all the structural changes seen could have been the secondary effects of a hypertension initially of functional origin. Primary pulmonary hypertension can certainly occur without intimal proliferation because cases are included in the series of Evans et al. (1957) and Wade and Ball (1957) in which arterial narrowing was found to be solely due to generalized contraction of the terminal muscular arteries.

Short (1957) considers that persistence of an increased tone in the smaller muscular arteries eventually leads to a state of permanent organic narrowing and indistensibility for which he uses 
the term arterial contracture. Arterial contracture, as described by Short, was present in at least two of our cases and its presence provides supporting evidence for postulating that the hypertension arose from increased vascular tone. Arterial contracture was seen in Case 1 in the occurrence of muscular arteries of arteriolar size, and in Case 3 of arteries with marked crenation of the elastic laminæ and the thickness of the wall increased relative to the diameter. In Case 2, only three blocks of lung tissue were available for examination and it was not possible to assess the incidence of contracture, but one artery of only $110 \mu$ external diameter was seen that showed crenated elastic laminæ and a thickened wall similar to the contracted arteries seen in Case 3 (Fig. 6).

We believe that the intimal proliferation, which was the most striking structural change seen in the pulmonary arteries in all three cases, was the result of thrombosis. In a few areas intimal proliferation was clearly due to the organization of thrombus. A thrombotic origin for all the intimal proliferation seems probable, for Duguid (1946 and 1954) has shown that where arteries are narrowed by fibrous thickening of the intima, thrombosis is the most likely cause.

Consideration must also be given to the congenital defects that occurred in other members of this family. A survey of only twenty-five subjects revealed one proven case of atrial septal defect associated with absence of the spleen and two further cases in which death in early infancy might have been due to congenital heart lesions. There was also one case of congenital dislocation of the hip and one case of hydrocephalus. Since hereditary tendencies account for a proportion of congenital lesions, there may have been present in our family a tendency not only for the development of pulmonary hypertension, but also for congenital lesions to occur in the heart and elsewhere.

Reference may be made again to the conception of "congenital pulmonary hypertension" developed by Evans and his colleagues. The conception has been extended to include the pulmonary hypertension that sometimes occurs in cases with certain cardiac and pulmonary lesions, for example, mitral stenosis, atrial septal defect, and emphysema (Evans, 1951; Evans and Short, 1957). When hypertension occurs in these cases, they postulate that it does so because of the presence, in addition to the associated lesion, of a congenital defect in the pulmonary vascular system. Evans considers that this congenital defect is medial hypoplasia, but his general conception remains valid even if it is thought the hypertension occurs as a result of a constitutional abnormality of function rather than an anatomical defect.

\section{SUMMARY AND CONCLUSIONS}

The clinical and pathological findings in three sibs who died from primary pulmonary hypertension are described.

It is considered that the disease was genetic in origin and the manner in which the genetic defect may have operated is discussed.

As well as to those mentioned in the text, we are greatly indebted to Dr. William Evans for advice and criticism, and to Dr. G. F. Walker for examining three members of the family resident in Peterborough. We also wish to thank Mr. P. Matthews and Mr. S. L. Shaw for technical assistance and Mr. S. Taylor for technical assistance and for the photomicrographs.

\section{REFERENCES}

Clarke, R. C., Coombs, C. F., Hadfield, G., and Todd, A. T. (1927). Quart. J. Med., $21,51$. Dresdale, D. T., Michtem, R. J., and Schultz, M. (1954). Bull. N.Y. Acad. Med., 30, 195.

Duguid, J. B. (1946). J. Path. Bact., 58, 207. (1954). Lancet, 1, 891.

Evans, W. (1951). Proc. Roy. Soc. Med., 44, 600.

- and Short, D. S. (1957). Brit. Heart J., 19, 457.

,-- , and Bedford, D. E. (1957). Brit. Heart J., 19, 93.

Gilmour, J. R., and Evans, W. (1946). J. Path. Bact., 58, 687.

Lange, F. (1948). Dtsch. med. Wsch., 73, 322.

Short, D. S. (1956). J. Fac. Radiol., 8, 118.

- (1957). Lancet, 2, 12.

Wade, G., and Ball, J. (1957). Quart. J. Med., 26, 83. 